\title{
Validation of Malayalam Version of the Voice Handicap Index
}

\author{
Unnikrishnan Menon, VS Sheejamol, Meera P Cherian
}

\section{ABSTRACT}

Background: It is important to have a subjective measure of hoarseness. This can be best achieved if the questionnaire is in the patient's own language.

Objective: To translate the voice handicap index (VHI) into the Malayalam language, and to evaluate its clinical validity and internal consistency.

Materials and methods: One hundred and six patients with dysphonia and 20 asymptomatic subjects were included in the study. Internal consistency was analyzed through Cronbach's alpha coefficient. For the clinical validity assessment, the scores obtained in the patient group were compared with those found in asymptomatic individuals through the Mann-Whitney U-test. Also, comparison between the VHI scores before and after phonomicrosurgery on 14 out of the studied 106 patients was done using the nonparametric Wilcoxon signed ranks test. Spearman rank correlation was used to find the effect of patient's age on VHI scores. Finally, the gender-wise average VHI score and its three subsets was analyzed using Wilcoxon signed ranks test.

Results: The internal consistency was found to be excellent $(\alpha=0.946)$. The control group scored significantly lower than the patients group $(p<0.001)$. Similarly, significant improvement was seen in the postoperative average VHI scores $(p<0.004)$. All of the preceding proves the validity of the translated questionnaire. Age showed a significant negative correlation for the overall VHI and their three domains $(p<0.001)$ in the dysphonic patients. There was no such correlation between male and female patient groups.

Conclusion: This Malayalam language version of the $\mathrm{VHI}$ questionnaire is a valid instrument for use in the voice clinic.

Clinical implication: Encouragement to all voice clinicians in India to develop and use the VHI in their native tongues.

Keywords: Dysphonia, Voice handicap index, Validation study.

How to cite this article: Menon U, Sheejamol VS, Cherian MP. Validation of Malayalam Version of the Voice Handicap Index. Int J Phonosurg Laryngol 2012;2(1):1-4.

\section{Source of support: Nil}

Conflict of interest: None declared

\section{INTRODUCTION}

The symptom of hoarseness is one that can affect the patient in different ways. This would depend on factors as varied as his/her personality, occupation and life-style. Consequently, the subjective handicap felt may not always correlate with the objective finding. This is in contrast to most other diseases where the physician can predict the patient's handicap from the diagnosis. In such a background, many subjective evaluation forms have been devised for the dysphonic patient. The most popular and validated one is the voice handicap index ( $\mathrm{V} \mathrm{HI}) .{ }^{1}$ It is now accepted as a useful tool in a dedicated voice clinic.

We have used a vernacular ( $M$ alayalam) version of the $\mathrm{VHI}$ questionnaire in our clinic. The present study is a pilot attempt to test its validity. A part from a Hindi version, this is the first ever such attempt in India.

\section{MATERIALS AND METHODS}

The adapted V HI form with all 30 questions translated into Malayalam was initially tested on a few patients in the general ENT OPD, along with discussion among the faculty. It was then administered to patients attending our voice clinic. For the purpose of this study, 106 consecutive patients completed the form. As controls, doctors and staff in ENT department (all asymptomatic for voice problems), 20 in number, were administered the form.

Surgical cases (microphonosurgery for vocal fold cysts and polyps) were administered another $\mathrm{VHI}$ form after due healing period following surgery. This was around 1 month postoperatively, depending on appointment to the clinic. These were 14 in number, and formed the group for comparison between pre- and postoperative $\mathrm{VHI}$ scores.

\section{Statistical Analyses}

The internal consistency of the translated questionnaire was analyzed through Cronbach's alpha coefficient. This is a statistical measure to determine the internal consistency among test items. A value of $\alpha>0.9$ is considered excellent, 0.8 to 0.9 ; good and $>0.7$; satisfactory. To confirm the internal consistency, a correlation was also done between each item and total VHI scores using Spearman rank correlation coefficient.

For the clinical validity assessment, the scores obtained in the patient group were compared with those found in asymptomatic individuals through the nonparametric $M$ annWhitney $U$-test. In addition, comparison between the pre and postoperative scores of 14 patients who underwent surgery was done using the nonparametric Wilcoxon signed ranks test.

Finally, the effect of age and gender on overall V HI and its three subscales were analyzed, using Spearman rank correlation and W ilcoxon signed rank test respectively. 
A Il statistical analysis was performed using the statistical software SA S 9.1 (Statistical A nalysis Software 9.1, SA S Institute Inc, Cary, NC).

\section{RESULTS AND OBSERVATIONS}

Total number of patients was $106(n=106)$.

There were 45 men and 61 women $(M=45$, $\mathrm{F}=61$ ).

M ean age of the patients was $39.09 \pm 14.35$ years, with a range of 9 to 75 . Out of these 106, 14 subjects underwent surgery $\left(S_{n}=14\right)$.

Controls (asymptomatic) subjects were 20. $\left(C_{n}=20\right)$. Their mean age was $26.1 \pm 7.3$ years, ranging from 18 to 41.

Internal consistency: This was found to be excellent (Cronbach's al pha $=0.946)$. There was high correlation for all the three domains vis-a-vis total VHI $(r=0.9086$, $0.87945,0.9321$ for functional, physical and emotional respectively). Similarly, the estimated correlation between each item and total V HI was al so found to be high (Table 1).

Validity: Total VHI score of control and patients were $0.6 \pm$ 2.087 and $46.877 \pm 25.395$ respectively. Thus, the control group scored significantly lower than the patient group $(p<0.001)$ on comparison of the average of three domain scores and total VHI score. The other statistic that we have checked is the comparison between the $\mathrm{VHI}$ scores of patients before and after microphonosurgery. It revealed a significant improvement in the average total VHI scores $(p<0.0042)$. The total VHI score before and after were $44.357 \pm 29.63$ and $25.571 \pm 23.441$ respectively (Tables 2 and 3 ).
Table 1: Correlation between individual item and total VHI and measurement of the reliability of the 30 items in Malayalam VHI using Spearman rank correlation coefficient

\begin{tabular}{|c|c|c|}
\hline Item & & $\begin{array}{l}\text { Item/total } \\
\text { VHI score } \\
\text { correlation }\end{array}$ \\
\hline Functional domain & $\begin{array}{l}\text { F1 } \\
\text { F2 } \\
\text { F3 } \\
\text { F4 } \\
\text { F5 } \\
\text { F6 } \\
\text { F7 } \\
\text { F8 } \\
\text { F9 } \\
\text { F10 }\end{array}$ & $\begin{array}{l}0.554763 \\
0.604252 \\
0.573853 \\
0.261536 \\
0.572615 \\
0.616014 \\
0.643048 \\
0.620909 \\
0.573752 \\
0.450341\end{array}$ \\
\hline Physical domain & $\begin{array}{l}\text { P1 } \\
\text { P2 } \\
\text { P3 } \\
\text { P4 } \\
\text { P5 } \\
\text { P6 } \\
\text { P } 7 \\
\text { P } \\
\text { P9 } \\
\text { P } 10\end{array}$ & $\begin{array}{l}0.520083 \\
0.470039 \\
0.667660 \\
0.410142 \\
0.686754 \\
0.715105 \\
0.535361 \\
0.709843 \\
0.444535 \\
0.461949\end{array}$ \\
\hline Emotional domain & $\begin{array}{l}\text { E1 } \\
\text { E2 } \\
\text { E3 } \\
\text { E4 } \\
\text { E5 } \\
\text { E6 } \\
\text { E7 } \\
\text { E8 } \\
\text { E9 } \\
\text { E10 }\end{array}$ & $\begin{array}{l}0.726945 \\
0.673231 \\
0.502268 \\
0.767420 \\
0.564717 \\
0.670778 \\
0.728060 \\
0.727107 \\
0.713887 \\
0.639329\end{array}$ \\
\hline
\end{tabular}

Cronbach's alpha 0.946705

Table 2: Comparison between the dysphonic patients and controls using nonparametric Mann-Whitney U-test

\begin{tabular}{|c|c|c|c|c|}
\hline \multicolumn{2}{|c|}{ Group } & \multirow{2}{*}{$\begin{array}{l}n \\
106 \\
20\end{array}$} & \multirow{2}{*}{$\begin{array}{c}\text { Mean } \pm S D \\
12.99 \pm 8.623 \\
0.2 \pm 0.8944\end{array}$} & \multirow{2}{*}{$\begin{array}{l}p \text {-value } \\
<0.001\end{array}$} \\
\hline Functional & $\begin{array}{l}\text { Patients } \\
\text { Control }\end{array}$ & & & \\
\hline Physical & $\begin{array}{l}\text { Patients } \\
\text { Control }\end{array}$ & $\begin{array}{l}106 \\
20\end{array}$ & $\begin{array}{c}20.841 \pm 8.992 \\
0.3 \pm 0.9234\end{array}$ & $<0.001$ \\
\hline Emotional & $\begin{array}{l}\text { Patients } \\
\text { Control }\end{array}$ & $\begin{array}{l}106 \\
20\end{array}$ & $\begin{array}{c}13.037 \pm 10.24 \\
0.1 \pm 0.447\end{array}$ & $<0.001$ \\
\hline Total VHI & $\begin{array}{l}\text { Patients } \\
\text { Control }\end{array}$ & $\begin{array}{l}106 \\
20\end{array}$ & $\begin{array}{c}46.877 \pm 25.395 \\
0.6 \pm 2.087\end{array}$ & $<0.001$ \\
\hline
\end{tabular}

Table 3: Comparisons of VHI (Domain and total) scores among before and after surgery using Wilcoxon rank signed test

\begin{tabular}{llll}
\hline Domain & Surgery & Mean \pm SD & p-value \\
\hline Functional & Before & $13.786 \pm 11.735$ & 0.0554 \\
& After & $8.1428 \pm 8.716$ & $0.0042^{*}$ \\
Physical & Before & $19.357 \pm 8.61$ & $0.0032^{*}$ \\
& After & $11.4285 \pm 7.812$ & $0.0042^{*}$ \\
Emotional & Before & $11.212 \pm 11.032$ & $5.00 \pm 8.1050$ \\
& After & $44.357 \pm 29.63$ & $24.571 \pm 23.441$ \\
\hline
\end{tabular}

*S tatistically significant at $p<0.05$ 
Table 4: Correlation between age and VHI (domain and total) scores among dysphonic patients and controls using Spearman rank correlation

\begin{tabular}{clc}
\hline Domain & \multicolumn{2}{c}{ Age } \\
\cline { 2 - 3 } & Patients & Control \\
\hline Functional & $r=-0.33948$ & $r=0.1806$ \\
& $p<0.001$ & $p=0.4461$ \\
Physical & $r=-0.41251$ & $r=0.29157$ \\
& $p<0.001$ & $p=0.2123$ \\
Emotional & $r=-0.32544$ & $r=0.1806$ \\
& $p<0.001$ & $p=0.4461$ \\
Total VHI & $r=-0.39391$ & $r=0.2897$ \\
& $p<0.001$ & $p=0.2154$ \\
\hline
\end{tabular}

Age and sex: In the patient group, age showed statistically significant negative correlation to the overall $\mathrm{VHI}$ score and to its three domains, namely, functional, physical and emotional. $\{-0.39391(p<0.001),-0.33948(p<0.001)$, $-0.41251(p<0.001),-0.39391(p<0.001)$ respectively $\}$. In the control group, age did not show significant correlation (Table 4).

A mong patients, the mean total $\mathrm{VHI}$ score for male subjects was $46.04 \pm 24.043$, while for the female subjects it was $47.04 \pm 26.530$; the difference was not statistically significant $(p=0.9669)$. The difference between mean scores of males and females functional, physical, emotional VHI scores was also not statistically significant $(p=0.516$, $p=0.093, p=0.7465$ respectively).

\section{DISCUSSION}

Role of $\mathrm{VHI}$ in the management of voice disorders: The voice handicap index has been proven beyond doubt as the preferred subjective evaluation score for dysphonic patients. Consisting of 30 questions, it was devised by J acobson et al in $1997 .{ }^{1}$ Literature search reveals many studies asserting its utility. ${ }^{2-4} 0$ ne article describes it as a useful instrument for quantifying the biopsychosocial impact of a voice disorder. $^{5}$

Role of translation: The true clinical advantage of a purely subjective questionnaire depends on its comprehensibility to the patient. To this end, it becomes essential that the questions be in the patient's native tongue. There are enough documented reports in literature of the $\mathrm{VHI}$ being adapted and validated into local languages all over the world..$^{6-8} \mathrm{~A} n$ Indian version has been described but with no language specification. ${ }^{9}$ Befittingly, a version in our national language, $\mathrm{Hindi}$, has been the first to be reported as validated. ${ }^{10}$ To the best of our knowledge, no other vernacular V HI has been reported from India. So, the present study is a first in that sense.

$M$ alayalam is the native language of the people of the state of K erala. It is spoken by approximately 35 million people, worldwide. Our Institution is a tertiary referral center in the premier metropolitan city in the state. A separate voice clinic was set up in the ENT department, consisting of the laryngostroboscope and voice analysis software. We felt the need for the VHI score too to complement the objective evaluation modalities. Soon, we realized the inadequacy of the process of the doctor or physician assistant translating each of the 30 questions of the English VHI form to the patient. Hence, the felt need for its translation.

Process of translation: The Mapi Research Institute monograph describes this in excellent detail. ${ }^{11}$ It states the ideal of the translated questionnaire to be its understandability to most respondents in a given population, irrespective of low education level. The full-fledged process of linguistic validation of a questionnaire should ideal ly consist of three steps. These are 'forward translation', 'backward translation' and 'patient testing'. ${ }^{11}$

Relevant to our M al ayalam adaptation, the first step was done as part of the dissertation project of an SLP student. The next step, viz. retranslating into English, was not attempted in a formal manner. Cursory oral checking was done in our department by the first author. Then the actual patient testing was done by administering the questionnaire. Here, the aim should be to check whether the translation is acceptable, with use of simple language such that it is understood in the clinically desired manner. ${ }^{11}$

It was al so tested on some of the patient's relatives, who were asymptomatic for any voice issue. After being sufficiently convinced that the above aims were achieved, we decided to proceed with the next logical step, i.e. validation of the form.

Our voice clinic is conducted weekly. All patients with voice complaints are referred here after basic screening. The Malayalam VHI forms were administered here with instruction regarding the importance of responses by the patient herself. A pproximate time taken to complete the form was found to be between 15 and 20 minutes. We noted occasional $(<10 \%)$ age and level of literacy-related difficulties in comprehension. These were addressed by the physician assistant in the clinic, taking care to avoid bias toward scoring.

Reliability testing for a questionnaire requires its repeat administration after a reasonable time gap, prior to starting any treatment. We have not been able to do this for the present study; timing and the natural course of management initiation being an issue. So, this is a lacuna to be filled. Other studies have reported reliability. ${ }^{10}$

\section{Statistical Analyses}

In the present study, the significant difference, in all three domains, between the scores of patients and asymptomatic 
controls proves the validity of our $\mathrm{M}$ alayalam version of VHI.

The other test that we have used is the difference between the scores of patients prior to and after undergoing surgery for the excision of benign vocal fold lesions. It has been proven that subjective and objective parameters improve after microphonosurgery for vocal fold cysts and polyps. ${ }^{12,13}$ This improvement is reflected in our VHI scores. We consider this as evidence of its construct validity.

In addition, we have studied the age and gender correlations also. Here, in contrast to few similar studies, we have found that older dysphonic patients tend to have lesser subjective complaints. No such difference was seen between the two sexes.

\section{CONCLUSION}

The $M$ al ayalam version of the standard voice handicap index questionnaire has been proved to be valid. This is an added, effective tool in the assessment of patients in our voice clinic. We hope that such vernacular adaptations are tried in other Indian languages too.

\section{ACKNOWLEDGMENT}

We would like to acknowledge the help and support of the A udiology Department of A mrita Institute of Medical Sciences and Research Centre in the data collection involved in this study.

\section{REFERENCES}

1. Jacobson B H, J ohnson A, Grywalski, et al. The voice handicap index (V HI): Development and validation. A m J Speech Lang Pathol 1997;6(3):66-70.

2. Schindler A, Bottero A, Capaccio P, Ginocchio D, A dorni F, Ottaviani $F$. V ocal improvement after voice therapy in unilateral vocal fold paralysis. J V oice 2008;22(1):113-18.

3. Thomas G, de J ong FICRS, Kooijman PGC, Cremers CWRJ . Utility of the Type $D$ scale and voice handicap index to assist voice care in students and teachers. Folia Phoniatr Logop 2006;58(4):250-63.

4. Hsiung $M W, L u P, K$ ang $B H, W$ ang $H W$. M easurement and validation of the voice handicap index in voice-disordered patients in Taiwan. J Laryngol Otol 2003;117(6):478-81.
5. M aertens $\mathrm{K}$, de J ong FI. The voice handicap index as a tool for assessment of the biopsychosocial impact of voice problems. B-ENT 2007;3(2):61-66.

6. Nunez-B atalla F, Corte-Santoz P, Senaris-Gonzal ez B, LlorentePendas J L, Gorriz-Gil C, Suarez-N ieto C. A daptation and validation to the Spanish of the voice handicap index (V HI-30) and its shortened version (V HI-10). A cta Otorrhinolaringol Esp 2007;58(9):386-92.

7. Malki KH, M esallam TA, Farahat M, Bukhari M, M urry T. $\checkmark$ alidation and cultural modification of A rabic voice handicap index. Eur A rchives of Oto Rhino Laryngol 2010;267(11): 1743-51.

8. XuW, Han D, Li H, Hu R, Zhang L. A pplication of the M andarin Chinese version of the voice handicap index. J Voice 2010;24(6):702-07.

9. Konnai RM, Jayaram M, Scherer RC. Development and validation of a voice disorder outcome profile for an Indian population. J V oice 2010;24(2):206-20.

10. Datta $R$, Sethi $A$, Singh $S$, Nilakantan A, V enkatesh MD. Translation and validation of the voice handicap index in $\mathrm{H}$ indi. J Laryngol V oice 2011;1(1):12-17.

11. V arni JW . Linguistic validation of the PedsQ $L^{T M}: A$ quality of life questionnaire. M api Research Institute.

12. Cheng J, W oo P. Correlation between the voice handicap index and voice laboratory measurements after phonosurgery. Ear Nose Throat J 2010;89(4):183-88.

13. Toran KC, Lal BK. Objective voice analysis for vocal polyps following microlaryngeal surgery. Kathmandu Univ Med J 2010;30(8):185-89.

\section{ABOUT THE AUTHORS}

\section{Unnikrishnan Menon (Corresponding Author)}

A ssistant Professor, Department of ENT, A mrita Institute of Medical Sciences and Research Centre, Kochi, Kerala, India e-mail: unnikrishnanmenon8@gmail.com

\section{VS Sheejamol}

Lecturer, Department of M edical B iostatistics, A mrita Institute of M edical Sciences and Research Centre, Kochi, K erala, India

\section{Meera P Cherian}

Physician A ssistant, D epartment of ENT, A mrita Institute of M edical Sciences and Research Centre, Kochi, K erala, India 